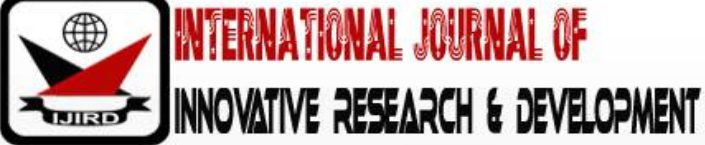

ISSN 2278 - 0211 (Online)

\section{Dietary Practices and Nutrition Status of Infants Born to Adolescent Mothers in Transmara West, Narok County, Kenya}

\begin{tabular}{c} 
Kotut Chebet Brigid \\
Post Graduate Student, Department of Human Nutrition and Dietetics, \\
Kabarak University, Kenya \\
Bor Wesley \\
Head of Department, Department of Human Nutrition and Dietetics, \\
Kabarak University, Kenya \\
Situma Jane \\
Lecturer, Department of Nutritional Sciences, \\
Masinde Muliro University of Science and Technology, Kenya \\
\hline
\end{tabular}

\begin{abstract}
:
Background: Infant and young child feeding practices contribute to the growth and development of infants as well as preventing the occurrence of common illnesses. Infants of young mothers are at risk of malnutrition because they are unprepared for child care.

Objectives: The purpose of this study was to determine dietary practices, health and nutrition status of infants born to adolescent mothers in Transmara West, Narok County.

Method: A descriptive cross-sectional study design was adopted and five health facilities were purposively selected in Transmara West sub county, Narok County. A sample size of 246 infants and 246 adolescent mothers were recruited from the selected health facilities. A semi-structured questionnaire was used to collect quantitative data which was analyzed using analyzed using SPPS for windows version 24.0 and ENA for SMART survey 2011. Chi-square and Pearson Product Correlation relationship was used to establish associations between variables at a significance level of $<0.05$. Result: The findings of the study revealed that most of the mothers were between 16 to 17 years with the youngest mother being 14 years old. The prevalence of wasting, stunting and underweight was 17.1\%, 22.0\% and 22.0\% respectively. The proportion of infants who were breastfed in the 24 hours preceding the study was as follows: $48.8 \%$ of 0-6months, 24\% 6-8 months and $27.2 \%$ of 9-12months. The children that attained the minimum dietary diversity in the age groups included; $37.4 \%$ and $53.9 \%$ for the age groups 6-8 months and 9-11 months respectively. Slightly less than half (46.3\%) of the infants received their recommended minimum meal frequency. Meal frequency and exclusive breastfeeding two weeks before the study were significant $(p<0.05)$ factors associated with malnutrition.

Conclusion: Based on the above outcome, it is recommended that more attention should be given to infants of young mothers. The government and other stakeholders should formulate policies that govern the health care and feeding practices of infants of adolescent mothers. Similar research should be replicated specially to compare the nutrition status of infants of adult mothers with that of young mothers.
\end{abstract}

Keywords: Feeding practices, health, Nutritional status, infant, adolescent mother

\section{Introduction}

Globally, approximately 12.8 million girls aged 15-19 years and two million girls under the age of 15 give birth every year putting themselves and their infants at risk due to complications of child birth and pregnancy (WHO, 2018). Infants born to adolescents who are considered young mothers are likely to have low birth weight, which can have an effect on their health and development (WHO,2018). Globally, approximately $22 \%$ of children under the age of five years were stunted, 5.6\% overweight and 7.5\% wasted globally while in Sub-Saharan Africa the prevalence of the three forms of malnutrition is stunting $5.6 \%$ overweight $21 \%$ and wasting is at $9 \%$ (WHO, 2018).

Early conceptions and childbearing have been associated with stress and negative mental health which impacts negatively in the development of their children (Huang, 2014). Most of the adolescent mothers may not be formally employed and are from low socioeconomic status which may affect the health outcomes of their infants (Godbout, Goldsberry, \& Franklin, 2016). They also deal with individual, social and personal changes which make it hard for them to properly take care of their infants (Chen et al., 2014).

The Kenya Demographic Health Survey (KDHS, 2014) reported that; $26 \%$ of children below the age of five years in Kenya are stunted, $4 \%$ wasted and $11 \%$ underweight based on WHO 2006 reference growth standards. In addition, $18 \%$ of young women aged 15-19 years have begun childbearing, 15\% have already had a live birth and an additional 3\% are 
pregnant with their first child (KDHS, 2014). According to the survey young women with no education (33\%) are much more likely to have begun childbearing compared to those with secondary or higher education (12\%). This makes it difficult for them to take care of their infants because of economic challenges (Population Reference Bureau, 2015). In urban residents of Kenya, adolescent mothers with primary education had their first child early than those with secondary education (Mumah, Kabiru, Izugbara, \& Mukiira, 2014).

In Narok County, global acute malnutrition prevalence remained poor as compared to that of June 2013 ( Narok County SMART Survey Report - February 2018, n.d.). The levels of malnutrition were as follows; underweight and stunting levels were at $18.9 \%$ and $27.2 \%$ respectively. Stunting levels was classified as medium that is 1 in 4 children in the county are stunted (Narok County SMART Survey Report - February 2018, n.d.). Additionally, Narok County has relatively higher levels of adolescent childbearing nationally.

\subsection{Statement of the Problem}

Despite adequate nutrition being a basic human right, newborns of adolescent mothers have been found to have poorer nutritional status as compared to their adult counterparts (Nguyen et al., 2017). Adolescent mothers have social, economic and maturity challenges that are unique to them which may in turn affect their health outcomes and that of their children (Godbout et al., 2016). Early marriage and child birth continue to increase in low- and middle-income countries. There is a rise in adolescent motherhood in Kenya with those with lower education and living in rural areas (26\%) having their child below the age of 18 years putting their children at risk of under nutrition (KDHS, 2014). In Transmara West County, there were high pregnancies that led to a high number of teenage girls dropping out of school which was so far the highest in the County (NATIONAL ADOLESCENTS AND YOUTH COUNTY, 2017). Further, a research by Okeyo (2019) in Transmara East established that there is low coverage of advice on healthy dietary diversity, exclusive breast feeding, nutrition supplementation, food fortification and complementary feeding which can create risks of under nutrition to the infants of these young mothers.

Under nutrition among their infant's increases the risk of morbidity and other serious health problems early in life. In addition, evidence has shown that young mothers struggle with different barriers such as the lack of autonomy in decision making and child care, the knowledge on proper infant feeding, embarrassment that is associated with public breastfeeding and the lack of support from the health care team (Jama et al., 2018). It has also been suggested that this is as a result of the stigma and perceived lack of support from the family, community and health care team.

Despite the rise in early motherhood in Kenya, there is a paucity of scientific data on dietary practices, health and nutritional needs of their infants. If no intervention is provided to these young mothers, the outcome may be associated with intergenerational malnutrition and poverty (Wanjohi et al., 2017). These young mothers are vulnerable, immature and not mentally prepared for child care. They have been found to be depressed and to have low self esteem as a result of child marriage (Marangu et al., 2017). Also, the return to school of the teenage mother leaves their infants vulnerable to under nutrition as the caretakers lack the proper motherly care and support. Narok County has high level of teenage pregnancies with poor malnutrition levels (Narok County SMART Survey Report - February 2018, n.d.).

The health and nutrition status of these infants of young mothers has received little attention and therefore merits further research especially in developing countries where dietary practices are rarely reported. To address this gap, this study aimed at determining dietary practices, health and nutritional status among infants of adolescent mothers in Transmara West Sub County.

\subsection{Purpose of the Study}

The purpose of this study was to:

- Determine the dietary practices of infants born to adolescent mothers in Transmara West, Narok County

- Assess the nutrition status of infants born to adolescent mothers in Transmara West, Narok County

- Establish the relationship between dietary practices and nutrition status of infants belonging to adolescent mothers in Transmara West, Narok County

\subsection{Research Questions}

- What are the dietary practices among infants born to adolescent mothers in Transmara West Narok County Kenya?

- What is the nutrition status of infants born to adolescent mothers in Transmara West Narok County Kenya?

- What is the relationship between dietary practices and nutrition status of infants belonging to adolescent mothers in Transmara West, Narok County Kenya?

\subsection{Significance of the Study}

The result of this study may help in planning purposes in order to meet Sustainable Development Goal number 3 that aims to promote good health and well being.

The findings of this study will provide evidence as to whether children of the adolescent mothers are at risk of malnutrition. The findings may enable the researchers to come up with programs to educate the adolescents on proper child care practices and infant feeding.

The findings from this study may help government and other stakeholders to come up with policies that will look up to the needs of the children of adolescent mothers. The identification of the factors associated with infant nutritional status among the adolescent mothers will reduce mortality and frequent hospitalization of children through designing programs targeting the adolescent mothers. 
The findings will be significant in improving the overall nutrition status of the infants of young mothers.

\section{Methodology}

\subsection{Research Design}

Descriptive cross-sectional study design was used to assess dietary practices, health and nutrition status of infants of adolescent mothers. This study design was used because it provides a snapshot of information about the situation at hand at one specific time and the characteristics of the status of study population.

\subsection{Research Setting}

The study was conducted at selected health facilities in Transmara West Sub-County namely Transmara SubCounty hospital, Lolgorian Sub-county hospital, St. Joseph missionary hospital, Nkararo health centre and Enosaen health centre where the research data was collected for the purpose of this study.

Transmara West Sub County is a rural sub-county with highest number of teenage pregnancies (County Health Report, 2013). The health facilities in Transmara West Sub County were stratified per levels such that level 2 was dispensaries, while level 3 was health centers and finally level 4 was district hospital.

\subsection{Research Study Population}

The population of this study consisted of adolescent mother infant pair. Infants who were aged 1-11 months at the time of the study and were born of adolescent mothers were considered for recruitment into the study. The age of the adolescent mother was between 12-18 years.

\subsection{Sample Size Determination}

The sample size was determined by using Fisher's et al., 1998 equation $n=\left(z^{2} \times p q\right) / d^{2}$ where the total population is greater than 10,000 .

$\mathrm{n}=$ desired sample size

$Z=$ standard normal deviate at the required confidence level in this case 1.96

$\mathrm{P}=$ proportion of the target population estimated to have characteristic being measured

Proportion of adolescent mothers either pregnant or lactating is $20 \%$ (KDHS, 2014) hence 0.20

$q=(1-\mathrm{p})=25 \%$ or 0.25

$d=$ level of accuracy of the statistic being measured $(95 \%)=(0.05)$

$n=\left(1.96^{2} \times(0.2 \times 0.25) / 0.05^{2}\right.$

$n=246$

The sample size (n) that was selected was 246 .

\subsection{Sampling Technique}

A purposive technique was used to select the health facilities where the adolescent mothers were selected through systematic sampling technique as they attended the mother child clinic.

\subsection{Instrumentation}

A semi-structured researcher administered questionnaire that was used to gather information on demographic and socio-economic characteristics, dietary practices, anthropometric measurements, care and support and morbidity patterns from adolescent mothers attending well baby clinic/MCH.

\subsection{Pretesting of the Study}

Pretesting of the questionnaires was done in Narok County Referral hospital which was not included in the study on $10 \%$ of the total sample. The area was selected for the pretest because it is the main referral in that County with high attendance of teenage mothers.

\subsection{Research instrument}

\subsubsection{Validity}

The researcher used peer review to enhance face and content validity. Data collection was also supervised very closely by the researcher. Questionnaires were reviewed daily to check for any inconsistencies.

\subsubsection{Reliability}

In order to produce consistency in results, split half was used for external reliability whereas Cronbach alpha $(\alpha)$ was used for internal reliability to ensure consistency of results.

\subsection{Data Collection Method}

Authorization was given by the facility in charges and nutritionists in the sampled health facilities. Adolescent mothers and their guardians gave consent for participation of their infants and young teenage mothers into the study respectively. The health staff in charges allowed the use of the available Salter scales and length boards. 


\subsection{Data Analysis}

The descriptive data collected was analyzed using statistically through Statistical Product and Services Solution (SPSS Version 24) and IBM. Findings were described using mean, maximum, minimum, standard deviation and percentages.

\subsection{Ethical Consideration}

An approval was obtained from the Kabarak University Institutional Ethical Review Committee (KU-IERC). Further authorization was given by the facility in charges and nutritionists in the sampled health facilities. Adolescent mothers and their guardians gave consent for participation of their infants and young teenage mothers into the study respectively. The health staff in charges allowed the use of the available Salter scales and length boards.

\section{Results}

\subsection{Demographic Characteristics of the Adolescent Mother and the Infant}

\begin{tabular}{|c|c|c|}
\hline & Frequency & Percentage \\
\hline & Age of the mother & \\
\hline 14 & 7.0 & 2.8 \\
\hline 15 & 15 & 6.1 \\
\hline 16 & 74 & 30.1 \\
\hline 17 & 80 & 32.5 \\
\hline \multirow[t]{2}{*}{18} & 70 & 28.5 \\
\hline & $\begin{array}{l}\text { Age group of the } \\
\text { infant }\end{array}$ & \\
\hline $1-6$ months & 120 & 48.8 \\
\hline 6-8 months & 59 & 24.0 \\
\hline \multirow[t]{2}{*}{ 9-12 months } & 67 & 27.2 \\
\hline & Gender of the infant & \\
\hline Male & 140 & 56.9 \\
\hline Female & 106 & 43.1 \\
\hline \multirow[t]{2}{*}{ Total } & 246 & 100.0 \\
\hline & Marital status & \\
\hline Married & 91 & 37 \\
\hline Single & 128 & 52 \\
\hline Separated & 7 & 2.8 \\
\hline Cohabiting & 20 & 8.1 \\
\hline Married & 91 & 37 \\
\hline Total & 120 & 100.0 \\
\hline
\end{tabular}

Table 1: Demographic Characteristics of the adolescent mother and the infant

The socio-demographic characteristic of the adolescent mother shows that most of the mothers were aged between 16 to 18 years with the youngest and oldest mothers being 14 and 18 years respectively (Table 1). The findings in this study indicated that most of the infants (48.8\%) were in the age group 1-6 months, the category of 6-8 months was (24\%) while those 9-12 months were (27.2\%). The gender of the infants shows that 56.9\% of the infants are female while $43.1 \%$ are male. The study revealed that half (52\%) of the respondents were single whilst the rest were either married (37 $\%)$ or cohabiting (7\%).

\subsection{Dietary Practices}

\subsubsection{Breastfeeding Practices}

- Research Question 1: What are the dietary practices among infants born to adolescent mothers in Transmara West Narok County Kenya? 


\begin{tabular}{|c|c|c|}
\hline Breast Feeding Practices & Frequency & Percentage \\
\hline Early initiation of breastfeeding (1-12months) \\
\hline After one hour & 93 & 37.8 \\
\hline Within the first one hour & 153 & 62.2 \\
\hline Foods given in the first hour & 7.7 \\
\hline Salt and water & 19 & 1.6 \\
\hline Sugar and water & 4 & 7.3 \\
\hline Cow's milk & 18 & .4 \\
\hline Nothing given & 1 & 97.2 \\
\hline Reason for giving other fluids before 6 months \\
\hline The baby was crying & 7 & 2.8 \\
\hline I had no milk & 24 & 9.8 \\
\hline Cultural/religious reasons & 5 & 2.0 \\
\hline Reason not given & 8 & 3.2 \\
\hline Exclusive breastfeeding under six months \\
\hline Yes & 123 & 82.2 \\
\hline No & 123 & 50.0 \\
\hline Total & 246 & 50.0 \\
\hline
\end{tabular}

Table 2: Showing the Breastfeeding Practices

According to the findings, half (50\%) of infants less than 6 months of age were exclusively breastfed. Some of the liquids that were given to the infants before six months of age included; water (7.7\%), sugar and water (7.3\%) and salt and water (1.6\%). Some of the reasons given for early introduction of liquids included; the mother had no milk (9.8\%), were advised by the health worker (2.0\%) despite policies and guidelines against early introduction of other feeds.

\subsubsection{Complementary Feeding Practices}

\begin{tabular}{|c|c|c|}
\hline & Frequency & Percentage \\
\hline Lower $\leq 3$ & 51 & 20.7 \\
\hline Medium 4-5 & 60 & 24.4 \\
\hline High $\geq 6$ & 4 & 1.6 \\
\hline Total & 115 & 100.0 \\
Mean 1.59 (SD 0.56) & & \\
\hline
\end{tabular}

Table 3: Showing the Dietary Diversity Score of Food Groups Consumed by the Infants

The mean dietary diversity score among the infants was 1.59 (SD 0.56) where nearly all the infants were in the lower and medium quartile. The minimum number of foodsconsumed was 1 while the maximum was 3 food groups. Infants consuming $\leq 3$ food groups were considered to have low dietary diversity score while those consuming 4 or 5 and $\geq 6$ were considered to have a medium and high dietary diversity score respectively. As shown in Table 3 , most of the infants were in the lower and medium terciles.

\subsection{Nutritional Status of the Infants}

- $\quad$ Research Question 2: What is the nutrition status of infants born to adolescent mothers in Transmara West Narok County Kenya?

\subsubsection{Acute Malnutrition (Wasting) Based on z-scores}

\begin{tabular}{|c|c|c|c|}
\hline & \multicolumn{2}{|c|}{ Gender of the Infant } & All \\
\cline { 2 - 4 } & Female(n=140) & Male(n=106) & $204(82.9 \%)$ \\
\hline Global malnutrition (<-2z-score) & $123(87.9 \%$ & $81(76.4 \%)$ & $32(13.0 \%)$ \\
\hline $\begin{array}{c}\text { Moderate malnutrition }(<-2 \text { z-score } \\
\text { and } \geq-3 \text { z-score) }\end{array}$ & $13(9.3 \%)$ & $19(17.9 \%)$ & $10(4.1 \%)$ \\
\hline Severe malnutrition (<-3z-score) & $4(2.9 \%)$ & $6(5.7 \%)$ & 10 \\
\hline
\end{tabular}

Table 4: Showing the Acute Malnutrition (Wasting) by Gender Based on Z-scores

More boys (17.9\%) had low weight for their length (wasting) than girls (9.3\%) 


\subsubsection{Stunting Based on z-scores}

\begin{tabular}{|c|c|c|c|}
\hline & \multicolumn{2}{|c|}{ Gender of the Infant } & All \\
\cline { 2 - 3 } & Female(n=140) & Male(n=106) & n=246 \\
\hline Stunting $(<-2 \mathrm{z}$-score) & $118(84.3 \%)$ & $74(69.8 \%)$ & $192(78.0 \%)$ \\
\hline $\begin{array}{c}\text { Moderately stunted }(<-2 \text { z-score and } \geq- \\
\text { 3 z-score) }\end{array}$ & $13(9.3 \%)$ & $16(15.1 \%)$ & $29(11.9 \%)$ \\
\hline Severely stunted (<-3z-score) & $9(6.4 \%)$ & $16(15.1 \%)$ & $25(10.2 \%)$ \\
\hline
\end{tabular}

Table 5: Stunting by Gender Based on Z-scores

More boys (15.1\%) were short for their age than girls $(9.3 \%)$ while stunting was highest in the age group 1-6 months (17.5\%) (Table 5)

\subsubsection{Underweight Based on z-scores}

\begin{tabular}{|c|c|c|c|}
\hline \multirow{2}{*}{} & \multicolumn{2}{|c|}{ Gender of the infant } & \multirow{2}{*}{$\begin{array}{c}\text { All } \\
\text { n=246 }\end{array}$} \\
\cline { 2 - 3 } & Female(n=140) & Male(n=106) & $173(70.3 \%)$ \\
\hline Underweight $(<-2 z-$-score) & $107(76.4 \%)$ & $66(62.3 \%)$ & $12(17.1 \%)$ \\
\hline $\begin{array}{c}\text { Moderately underweight (<-2 z-score and } \\
\geq-3 \text { z-score) }\end{array}$ & $23(16.4 \%)$ & $19(17.9 \%)$ & $420)$ \\
\hline Severely underweight (<-3z-score) & $4(2.9 \%)$ & $8(7.5 \%)$ & $12(4.9 \%)$ \\
\hline
\end{tabular}

Table 6: Showing Underweight by Gender Based on Z-scores (Table 6)

About $22.0 \%$ of all the children in the study had a low weight for their age with only $17.9 \%$ originating from boys

\subsection{Relationship between dietary practices and nutrition status}

- $\quad$ Research Question 3: What is the relationship between dietary practices and nutrition status of infants belonging to adolescent mothers in Transmara West, Narok County, Kenya?

3.4.1 Relationship between Exclusive Breastfeeding and Nutritional Status

\begin{tabular}{|c|c|c|c|}
\hline \multirow{2}{*}{ Variable } & \multicolumn{2}{|c|}{ Exclusive Breastfeeding } & \multirow{2}{*}{ P-value* $^{*}$} \\
\cline { 2 - 3 } & Exclusive & Not exclusive & \multirow{2}{*}{$0.001^{*}$} \\
\hline Wasting & & \\
\hline Normal & $91(74.0 \%)$ & $113(91.9 \%)$ & \\
\hline Moderately wasted & $22(17.9 \%)$ & $10(8.1 \%)$ & \multirow{2}{*}{0} \\
\hline Severely wasting & $10(8.1 \%)$ & $0(0.0 \%)$ & \multirow{2}{*}{$0.001^{*}$} \\
\hline Underweight & & & \multirow{2}{*}{} \\
\hline Normal & $93(75.6 \%)$ & $80(65.0 \%)$ & \multirow{2}{*}{$0.001^{*}$} \\
\hline Moderately underweight & $12(9.8 \%)$ & $30(24.4 \%)$ & \\
\hline Severely underweight & $1(.8 \%)$ & $11(8.9 \%)$ & \\
\hline Overweight & $16(13.8 \%)$ & $2(1.6 \%)$ & \\
\hline Stunting & & & \\
\hline Normal & $77(62.6 \%)$ & $115(93.5 \%)$ & \\
\hline Moderately stunted & $24(19.5 \%)$ & $5(4.1 \%)$ & \\
\hline Severely stunted & $22(17.9 \%)$ & $3(2.4 \%)$ & \\
\hline
\end{tabular}

Table 7: Showing Relationship between Exclusive Breastfeeding and Nutritional Status

There was a significant relationship between exclusive breastfeeding and nutritional status based on underweight, wasting and stunting. Most infants (50\%) were exclusively breastfed for a period of six months (chi-square test; $\mathrm{p}=0.000$ ) (Table 7) 


\subsubsection{Relationship between Meal Frequency and Nutritional Status}

\begin{tabular}{|c|c|c|c|c|c|c|}
\hline \multicolumn{2}{|c|}{ Variable } & \multicolumn{4}{|c|}{ Food Frequency } & \multirow[t]{2}{*}{ P-value* } \\
\hline & & & Below 3 & $3-4$ & Above 4 & \\
\hline \multirow{2}{*}{ Underweight } & $\begin{array}{c}\text { Moderately } \\
\text { underweight }\end{array}$ & $12(28.60 \%)$ & $0(0.00 \%)$ & $0(0.00 \%)$ & $30(71.40 \%)$ & \multirow[t]{2}{*}{$0.001^{*}$} \\
\hline & $\begin{array}{c}\text { Severely } \\
\text { underweight }\end{array}$ & $1(8.30 \%)$ & $0(0.00 \%)$ & $0(0.00 \%)$ & 11(91.70\%) & \\
\hline \multirow[b]{3}{*}{ Stunting } & Normal & $79(41.10 \%)$ & $4(2.10 \%)$ & $0(0.00 \%)$ & $109(56.80 \%)$ & \multirow[t]{3}{*}{$0.001^{*}$} \\
\hline & $\begin{array}{c}\text { Moderately } \\
\text { stunted }\end{array}$ & $24(82.80 \%)$ & $2(6.90 \%$ & $0(0.00 \%)$ & $3(10.30 \%)$ & \\
\hline & $\begin{array}{l}\text { Severely } \\
\text { stunted }\end{array}$ & $22(88.00 \%)$ & $0(0.00 \%)$ & $1(4.00 \%)$ & $2(8.00 \%)$ & \\
\hline \multirow[b]{3}{*}{ Wasting } & Normal & $93(45.60 \%)$ & $5(2.50 \%)$ & $1(0.50 \%)$ & $105(51.50 \%)$ & \multirow[t]{3}{*}{$0.011^{*}$} \\
\hline & $\begin{array}{c}\text { Moderately } \\
\text { wasted }\end{array}$ & $22(68.80 \%)$ & $1(3.10 \%)$ & $0(0.00 \%)$ & $9(28.10 \%)$ & \\
\hline & $\begin{array}{l}\text { Severely } \\
\text { wasting }\end{array}$ & $10(100.00 \%)$ & $0(0.00 \%)$ & $0(0.00 \%)$ & $0(0.00 \%)$ & \\
\hline
\end{tabular}

Table 8: Showing Relationship between Meal Frequency and Nutritional Status

In this study, the three indices (underweight, wasting and stunting) showed a significant relationship with meal frequency (p-value $0.00,0.000$ and 0.011 respectively) (Table 8)

\section{Discussion}

The findings in this study showed that more than half of the infants were initiated to the breast within one hour of birth. The mothers who initiated after one hour cited no milk and cultural influence as the reasons for late initiation. This study agreed with that of Kabwijamu (2016) in Uganda and Kenya Demographic Health Survey (2014) where initiation within the first hour was $71 \%$ and $62 \%$ respectively. These results differed with that of Olodu (2019) where a higher number of infants were initiated within the first hour at $87 \%$. This could be explained by the fact that most young mothers attended post natal care and were others likely to receive information of infant feeding.

The achievement of minimum dietary diversity in this study was much higher than other studies carried out in Kenya by (Macharia 2018) and (Korir, 2014). In this study, almost all (91.3\%) of infants 6-11 months were reported to have consumed foods from $\leq 4$ food groups. Infants in the age groups 6-8 months and 9-12 months, (37.4\%) and (53.9\%) met the recommended levels respectively. Most of the infants had been introduced to solid and semi-solid foods by the age of 6 months as per WHO and UNICEF (2013) recommendations. The findings of this study are in agreement with the national data in Kenya (KDHS, 2014) where most of the infants frequently consumed foods rich in vitamin A, dairy products and grains.

The prevalence of wasting (17.1\%), stunting (22.0\%) and underweight (19.1\%) were above that reported in the KDHS 2014 where wasting, stunting and underweight for children 6-59 months were 4.0\%, 26.0\% and 11.0\% respectively. The findings of this study were also higher than that of Wemakor (2018) in Ghana except for stunting which was lower. The findings were also similar to the County Health report (2018) where stunting was $27.2 \%$ while severe stunting was $7.7 \%$ and underweight $18.9 \%$ while severe underweight was $2.6 \%$.

The findings in this study support the view that the prevalence of malnutrition among infants of young mothers has remained high because these mothers are not ready for child care. In all three forms of malnutrition (stunting, wasting and underweight), boys had a higher prevalence than girls. This was also similar to the Narok County Health report of 2018 where boys had a higher malnutrition level than girls.

The under nutrition among the males children could be as a result of food preference, serving more food in favor of a girl child. This finding agreed with the findings of Nguyen (2017) showing that malnutrition is indeed a teething public health problem among infants of young mothers. The problem is further compounded by teenage motherhood that is not yet adequately prepared to shoulder the responsibility of childcare which is one of the causes of childhood malnutrition. The association between meal frequency, breastfeeding and nutrition status was established. Achievement of minimum meal frequency and minimum acceptable diet is associated with better nutritional status of infants. Most infants met this recommendation and thus had a good nutritional status. This agreed with the finding in Nigeria where infants who did not receive appropriate feeding had higher odds for wasting, stunting and underweight (Olodu et al., 2019).

\section{Limitation of the Study}

The study was a cross-sectional design carried out among infants aged 0-11 months in which cause effect relationship may not have been established. Secondly, the study was conducted within the facility and therefore a number of teenagers who may have delivered at home could have been missed at the enrolment. Thirdly, the data was collected through the questionnaire which relied on recall, hence subject to respondent bias. To mitigate this, the questions were broken down into sections during administration for easier understanding like on initiation of breastfeeding it was 
specifically grouped into hours to enable more accurate recall.

\section{Conclusions}

The results of this study showed that most of the respondents were young teenage women of primary level of education. As compared to the National rates of malnutrition by Kenya Demographic Health Survey (2014), the prevalence of under nutrition among the infants was higher. Infant feeding practices showed a positive significant relationship with nutritional status. Additionally, the importance of exclusive breastfeeding was highlighted through the positive association between exclusive breastfeeding and nutrition status.

\section{Recommendations}

From this study, it can be recommended that government, health-facilitators, non-governmental organizations should provide ongoing training of the community and especially young mothers on IYCF. This will acquaint them with knowledge and skills to provide IYCF education and support to adolescent mothers in the study area and contribute to improved uptake of exclusive breastfeeding.

There is also a need to encourage more home visits by community health workers to follow-up and support infant and young child feeding practices to adolescent mothers in the study area. A similar study with a focus on caloric adequacy of the diet and food frequencies should be carried out in the same study area. This study looked at malnutrition among infants of young mothers. It would be beneficial to have a similar study that compares the feeding practices and nutritional status of infants belonging to adolescent mothers with those of adult mothers.

\section{References}

i. Abuya, B. A., Onsomu, E. O., Kimani, J. K., \& Moore, D. (2010). Influence of maternal education on child immunization and stunting in Kenya. Maternal and child health journal, 15(8), 1389-1399.

ii. Aparicio, E. M., Gioia, D., \& Pecukonis, E. V. (2018). "I Can Get Through This and I Will Get Through This ": The unfolding journey of teenage motherhood in and beyond foster care. https://doi.org/10.1177/1473325016656047

iii. Beguy, D., Mumah, J., \& Gottschalk, L. (2014). Unintended pregnancies among young women living in urban slums: Evidence from a prospective study in Nairobi City, Kenya. PLoS ONE, 9(7), 1-26. https://doi.org/10.1371/journal.pone.0101034

iv. Black, R. E., Victora, C. G., Walker, S. P., Bhutta, Z. A., Christian, P., De Onis, M., ... Uauy, R. (2013). Maternal and child undernutrition and overweight in low-income and middle-income countries. The Lancet, Vol. 382, pp. 427-451. https://doi.org/10.1016/S0140-6736(13)60937-X

v. Campbell, B., Martinelli-heckadon, S., \& Wong, S. (2013). Motherhood in Childhood.

vi. Chen, Y. J., Li, C. R., Lee, S. H., Hsu, B. Q., Wu, W. Y., Kuo, C. P., ... Lee, M. C. (2014). Growth changes in infants born of adolescent mothers: Results of a national cohort study in Taiwan. Iranian Journal of Reproductive Medicine, 12(11), 737-746.

vii. Concerns, D. (2017). International Journal of Social Influence of Early Marriage on the Care of Infants among Adolescent Mothers in Kiserian. 1(October), 52-64.

viii. County, N. (2013). CHRISTIAN AID Report of SMART Nutrition Survey. (July).

ix. da Costa, K. A. O., Antunes, M. M. de C., Cabral, P. C., \& da Silva, G. A. P. (2018). Feeding style of adolescent mothers and complementary feeding practice of their infants. Revista de Nutricao, 31(1), 49-58. https://doi.org/10.1590/1678-98652018000100005

x. Edilberto. (n.d.). ADOLESCENT PREGNANCY : A Review of the Evidence ADOLESCENT PREGNANCY : A Review of the Evidence.

xi. Fadare, O., Id, M. A., Mavrotas, G., Akerele, D., \& Ogunniyi, A. (2019). Mother's nutrition-related knowledge and child nutrition outcomes : Empirical evidence from Nigeria. 1-17.

xii. Finlay, J., Norton, M., \& Mejía-Guevara, I. (2017). Adolescent Fertility and Child Health: The Interaction of Maternal Age, Parity and Birth Intervals in Determining Child Health Outcomes. International Journal of Child Health and Nutrition, 6(1), 16-33. https://doi.org/10.6000/1929-4247.2017.06.01.2

xiii. Godbout, J. M., Goldsberry, W. N., \& Franklin, T. E. (2016). Factors Associated with Infant Feeding Choices in the Adolescent Population. https://doi.org/10.1177/0890334416662629

xiv. Islam, A., Islam, N., Bharati, P., Aik, S., \& Hossain, G. (2016). Socio-economic and demographic factors influencing nutritional status among early childbearing young mothers in Bangladesh. BMC Women's Health, 16(1). https://doi.org/10.1186/s12905-016-0338-y

xv. Jama, N. A., Wilford, A., Haskins, L., Coutsoudis, A., Spies, L., \& Horwood, C. (2018). Autonomy and infant feeding decision-making among teenage mothers in a rural and urban setting in KwaZulu-Natal, South Africa. BMC Pregnancy and Childbirth, 18(1). https://doi.org/10.1186/s12884-018-1675-7

xvi. Kabwijamu, L., Waiswa, P., Kawooya, V., Nalwadda, C. K., Okuga, M., \& Nabiwemba, E. L. (2016). Newborn Care Practices among Adolescent Mothers in Hoima District , Western Uganda. 1-12. https://doi.org/10.1371/journal.pone.0166405

xvii. Kimani-murage, E. W., Wekesah, F., Wanjohi, M., Kyobutungi, C., Ezeh, A. C., Musoke, R. N., ... Griffiths, P. (2015). Original Article Factors affecting actualisation of the WHO breastfeeding recommendations in urban poor settings in Kenya. 314-332. https://doi.org/10.1111/mcn.12161 
xviii. Mumah, J., Kabiru, C. W., Izugbara, C., \& Mukiira, C. (2014). Coping with Unintended Pregnancies: Narratives from Adolescents in Nairobi's Slums. STEP UP Research Report, (April). Retrieved from http://www.popcouncil.org/uploads/pdfs/2014STEPUP_APHRC-ResearchReport.pdf

xix. Narok County SMART Survey Report - February 2018. (n.d.).

xx. NATIONAL ADOLESCENTS AND YOUTH COUNTY. (2017). (January).

xxi. Nesbitt, S. A., Campbell, K. A., Jack, S. M., Robinson, H., Piehl, K., \& Bogdan, J. C. (2012). Canadian adolescent mothers ' perceptions of influences on breastfeeding decisions : a qualitative descriptive study. 1-14.

xxii. Nguyen, P. H., Sanghvi, T., Tran, L. M., Afsana, K., Mahmud, Z., Aktar, B., ... Menon, P. (2017). The nutrition and health risks faced by pregnant adolescents: Insights from a cross-sectional study in Bangladesh. PLoS ONE, 12(6). https://doi.org/10.1371/journal.pone.0178878

xxiii. Raj, A., Saggurti, N., Winter, M., Labonte, A., Decker, M. R., Balaiah, D., \& Silverman, J. G. (2010). The effect of maternal child marriage on morbidity and mortality of children under 5 in India: Cross sectional study of a nationally representative sample. BMJ (Online), 340(7742), 353. https://doi.org/10.1136/bmj.b4258

xxiv. Report, F. (2015). Focused Report on ... Infant Feeding among Adolescent Mothers. (June), 1-13.

xxv. Smith, P. H., Coley, S. L., Labbok, M. H., Cupito, S., \& Nwokah, E. (2012). Early breastfeeding experiences of adolescent mothers : a qualitative prospective study. 8-10.

xxvi. Tankoi, O., Pub, I. J., Safe, H., Sub-county, T. E., \& County, N. (2016). International Journal of Public Health \& Safety Determinants of Malnutrition among Children Aged 6-59 Months in. 1(3), 1-18.

xxvii. Tucker, C. M., Wilson, E. K., \& Samandari, G. (2011). Infant feeding experiences among teen mothers in North Carolina : Findings from a mixed- methods study. 1-11.

xxviii. UNICEF. (n.d.). Improving child nutrition : the achievable imperative for global progress.

xxix. Walgwe, E., Termini, N., Birungi, H., \& Undie, C.-C. (2016). Kenya: Helping adolescent mothers remain in school through strengthened implementation of school re-entry policies. (November). Retrieved from https://www.popcouncil.org/uploads/pdfs/2016STEPUP_AdolMothersKenya.pdf\%0Ahttp://www.popcouncil. org/uploads/pdfs/2016STEPUP_AdolMothersKenya.pdf

xxx. Wanjohi, M., Griffiths, P., Wekesah, F., Muriuki, P., Muhia, N., Musoke, R. N., ... Kimani-murage, E. W. (2017). Sociocultural factors influencing breastfeeding practices in two slums in Nairobi, Kenya. International Breastfeeding Journal, 1-8. https://doi.org/10.1186/s13006-016-0092-7

xxxi. Wemakor, A., Garti, H., Azongo, T., Garti, H., \& Atosona, A. (2018). Young maternal age is a risk factor for child undernutrition in Tamale Metropolis, Ghana. BMC Research Notes, 11(1). https://doi.org/10.1186/s13104018-3980-7

xxxii. World Health Organization. (n.d.). World Health Statistics 2018 : monitoring health for the SDGs : sustainable development goals.

xxxiii. Wu, W., Li, C., Kuo, C., Chiang, Y., \& Lee, M. (2016). The growth and development of children born to adolescent mothers in Taiwan. Italian Journal of Pediatrics, 1-6. https://doi.org/10.1186/s13052-016-0280-5

xxxiv. xxxiv. Yu, S. H., Mason, J., Crum, J., Cappa, C., \& Hotchkiss, D. R. (2016). Differential effects of young maternal age on child growth. Global health action, 9(1), 31171. 